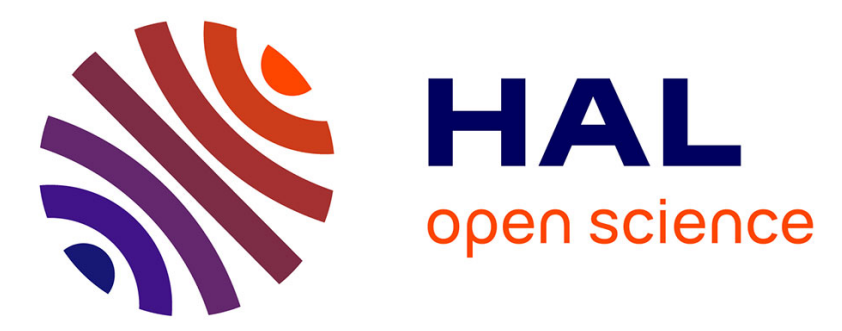

\title{
Oxygen supply management to intensify wastewater treatment by a microbial electrochemical snorkel
}

\author{
Morgane Hoareau, Luc Etcheverry, Benjamin Erable, Alain Bergel
}

\section{To cite this version:}

Morgane Hoareau, Luc Etcheverry, Benjamin Erable, Alain Bergel. Oxygen supply management to intensify wastewater treatment by a microbial electrochemical snorkel. Electrochimica Acta, 2021, 394, pp.139103. 10.1016/j.electacta.2021.139103 . hal-03338569

\section{HAL Id: hal-03338569 \\ https://hal.science/hal-03338569}

Submitted on 8 Sep 2021

HAL is a multi-disciplinary open access archive for the deposit and dissemination of scientific research documents, whether they are published or not. The documents may come from teaching and research institutions in France or abroad, or from public or private research centers.
L'archive ouverte pluridisciplinaire HAL, est destinée au dépôt et à la diffusion de documents scientifiques de niveau recherche, publiés ou non, émanant des établissements d'enseignement et de recherche français ou étrangers, des laboratoires publics ou privés. 


\title{
Oxygen supply management to intensify wastewater treatment by a microbial electrochemical snorkel
}

\author{
Morgane Hoareau, Luc Etcheverry, Benjamin Erable, Alain Bergel* \\ Laboratoire de Génie Chimique, Université de Toulouse, CNRS, INP, UPS, Toulouse, France
}

\section{A R T I C L E I N F O}

Article history:

Received 10 February 2021

Revised 30 July 2021

Accepted 12 August 2021

Available online 17 August 2021

Keywords:

Bioremediation

Electroactive biofilm

Microbial electrochemical system

Microbial fuel cell

Bioelectrochemical system

\begin{abstract}
A B S T R A C T
The microbial electrochemical snorkel (MES) is a low-cost, low-maintenance technology that could considerably reduce wastewater treatment costs by reducing the need for aeration. An MES is a single electrode. The lower part, in the anoxic zone of the bioreactor, oxidizes organic matter by transferring electrons to the electrode. The upper part, in the oxic zone, releases the electrons by reducing dissolved oxygen. This study gives new insights into the correlation between the MES potential, the concentration of dissolved oxygen and COD abatement, thus enabling practical rules to be extracted for running the MES in optimal conditions, particularly for adjusting the aeration zone and frequency.

Here, aeration promoted the cathodic reaction and increased the MES potential to a maximum $(0.0$ to $0.1 \mathrm{~V} / \mathrm{SCE})$. After aeration stopped, the potential dropped to a minimum $(<-0.4 \mathrm{~V} / \mathrm{SCE})$. With $26 \mathrm{~cm}$ high MESs, sequential aeration at the top was not sufficient to support an effective cathodic zone, while aeration at the bottom was detrimental to the formation of the microbial anode. With MESs $48 \mathrm{~cm}$ high and aeration set up in the highest quarter, 30 minutes of aeration every 4.5 hours gave potential variations that were stable for weeks. The MESs continued to oxidize organic matter 30 minutes after the aeration had stopped. In this period, the MESs removed 3 to 6.3 times more COD than the control reactors. Increasing the electrode capacitance is therefore suggested as an effective way to further decrease the aeration cost by decreasing the aeration frequency.
\end{abstract}

\section{Introduction}

Wastewater treatment plants consume large amounts of energy, which represent a significant portion of municipalities', and thus countries', electricity consumption [1], reaching, for example, $1 \%$ of the total energy consumed by Germany or Italy [2]. In this framework, supplying oxygen is the most cost-intensive operation of the aerobic biological treatment plants. The microbial electrochemical snorkel (MES) is a low-cost, low-maintenance technology that could considerably reduce the cost of the oxygen supply by reducing or even avoiding the need for aeration of the bioreactor.

An MES can be defined simply as a single electrode in an environment where the composition of oxidizing and reducing species is spatially heterogeneous. In the context of wastewater treatment, the lower part of the MES is positioned in the lower, anoxic part of the bioreactor and ensures the oxidation of the organic matter $[3,4]$. Anaerobic bacteria spontaneously form an electroactive biofilm on the surface of that part of the MES and oxidize organic matter by transferring electrons to the electrode. This part of the

\footnotetext{
* Corresponding author.

E-mail address: alain.bergel@toulouse-inp.fr (A. Bergel).
}

MES forms the anode, which acts as the electron acceptor for the exoelectrogenic bacteria. The upper part of the MES, located in the aerobic upper zone of the bioreactor, releases the electrons from the electrode by reducing oxygen. It constitutes the cathode. Different types of organic matter can be oxidized at the anode part, such as volatile fatty acids and hydrocarbons [5,6], and other electron acceptors than oxygen, e.g. nitrates [7], can be used at the cathode part. An MES can be considered as the simplest possible microbial fuel cell with short-circuited anode and cathode. As the anode and cathode are short-circuited, the MES does not produce any power but it supports the highest possible electrochemical reaction rates that an MFC could reach.

The first publication dedicated to an MES applied the concept to wastewater treatment [3]. The MES was compared with a microbial fuel cell (MFC) equipped with a resistance of $1000 \Omega$, a value commonly reported for MFCs. The chemical oxygen demand (COD) was abated by $40-50 \%$ with the MFC, while the abatement reached $60-75 \%$ with the MES. MESs in the form of beds of conductive granules have given impressive results for wastewater treatment in constructed wetlands [8]. The concept is then named METland (Microbial Electrochemical Technology in constructed wetland). Compared to a conventional treatment lagoon equipped with 
non-conductive gravel, a METland designed with conductive granules resulted in COD and $\mathrm{BOD}_{5}$ reductions 3 and 4.5 times higher, respectively. The MES allowed the legal discharge thresholds of $125 \mathrm{mg} . \mathrm{L}^{-1}$ of COD and $25 \mathrm{mg} . \mathrm{L}^{-1}$ of $\mathrm{BOD}_{5}$ to be reached with a considerably shorter hydraulic retention time ( 0.5 day) than the gravel-containing control (3.4 days) [9]. In the treatment of pig slurry, the COD reduction reached $90 \%$ with METland compared to $81 \%$ with a lagoon containing a sand bed [10]. This process has also proven to be effective for nitrogen and phosphate treatment [11].

Despite clearly promising successes, MESs, like MFCs, show performance levels that are severely limited by the low oxygen reduction rate at the cathode part $[12,13]$. On the one hand, no catalyst is really efficient at $\mathrm{pH}$ values around neutrality [14]. On the other hand, the concentration of dissolved oxygen is very low, around $9.09 \mathrm{mg} / \mathrm{L}$ at $20^{\circ} \mathrm{C}$ in water $(0.28 \mathrm{mM})$, and its transport to the MES surface is consequently slow in the absence of stirring or forced aeration. It is essential to deal with the issue of oxygen supply management if the objective is to scale up MESs for wastewater treatment. It is necessary to find the delicate balance between increasing the mass transfer of oxygen to the MES and keeping the cost of aeration as low as possible.

The purpose of the present work was to optimize the oxygen supply in an MES. The challenge was to provide the MES with the amount of oxygen required for the extraction of electrons without hindering the oxidation reaction, which requires anoxic conditions. Two strategies for doing this were investigated.

In Strategy 1, the objective is to establish a stable profile of dissolved oxygen inside a bioreactor with a lower, anoxic zone and an upper, oxic one. The cathode develops in the upper zone, which is sequentially aerated, while, hopefully, the anoxic bottom is not reached by oxygen. In this way, it should be possible to achieve significant cost savings in wastewater treatment plants by aerating only the upper part of a bioreactor equipped with an MES.

In Strategy 2, the whole bioreactor is aerated sequentially, as is currently done in usual aerobic WW bioreactors. In this case, the whole electrode sequentially behaves as an anode, when it is not aerated, and as a cathode, when it is aerated. When placed in anoxic conditions, the electrode oxidizes organic matter by accepting electrons (anode). Conversely, when placed in oxic conditions, the electrode releases the electrons by reducing oxygen (cathode). So-called bidirectional microbial electrodes have been shown to be efficient for both oxygen reduction and organic matter oxidation $[15,16]$. In Strategy 2, the hope is that the presence of the MES, acting as a bidirectional electrode, will reduce the frequency of aeration compared to current WW treatment bioreactors with no MES.

Besides checking these two strategies, this work demonstrated that the potential of the MES and the soluble oxygen concentration are closely related. Furthermore, the efficiency of the COD abatement by MES also depended on the potential. The MES potential is thus shown to be the key parameter that should be monitored in order to optimize the MES operating protocol. This conclusion has already been speculated theoretically [4] but is demonstrated experimentally for the first time here. Furthermore, the monitoring of the potential allowed us to define the phase during which the MES is the most efficient in terms of COD abatement and thus gives a practical tool to optimize the operating parameters.

\section{Materials and methods}

\subsection{Media and electrochemical set-up}

Domestic wastewater (WW) was collected from the aerobic tank of a WW treatment plant (Castanet-Tolosan, near Toulouse, France) and used without any addition. When indicated, it was inoculated with $5 \%(\mathrm{v} / \mathrm{v})$ of activated sludge (AS) collected from

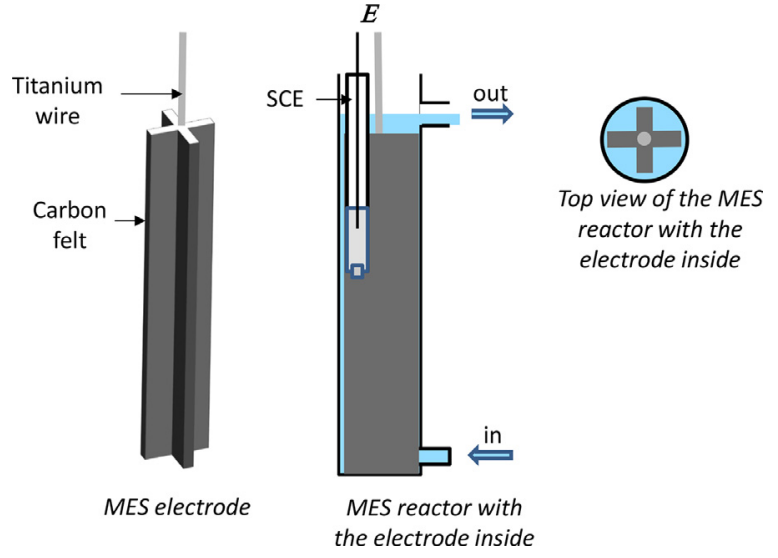

Fig. 1. Diagram of MES reactor and MES electrode

the same aerobic tank. In some cases, when indicated, hydrolysed WW was used to stabilize the soluble COD (Chemical Oxygen Demand) content. Hydrolysis consisted of maintaining fresh WW under anaerobic conditions during one week at room temperature. This process increased the soluble COD from $150-250 \mathrm{mg} \mathrm{O} \cdot \mathrm{L}^{-1}$ in fresh WW to $250-350 \mathrm{mg} \mathrm{O} \cdot \mathrm{L}^{-1}$ in hydrolysed WW.

Two different MES configurations were used, called MES_26 and MES_48, because they were equipped with electrodes $26 \mathrm{~cm}$ and $48 \mathrm{~cm}$ high, respectively. Both set-ups were made of vertical glass cylinders of small diameter and large height in order to stabilize an aerobic upper zone and an anaerobic lower zone more easily (objective of Strategy 1). In addition, the reactors were filled with a large volume of electrode over their entire height (Fig. 1) in order to approximate the situation of a liquid column in a bioreactor.

Each MES_26 electrode was made of two strips of carbon felt sheet (RVG 4000, Mersen, France) $4 \mathrm{~cm}$ wide, $0.5 \mathrm{~cm}$ thick and 26 $\mathrm{cm}$ high, assembled in a cross shape with a titanium rod $(1 \mathrm{~mm}$ in diameter) in the centre over the whole height (Fig. 1). The MES_26 reactors were glass cylinders $4.2 \mathrm{~cm}$ in diameter, which contained WW to a height of $27 \mathrm{~cm}$, i.e. the solution surface was $1 \mathrm{~cm}$ above the electrode.

The MES_48 electrodes were similar to the MES_26 ones but with a height of $48 \mathrm{~cm}$ and a width of $3 \mathrm{~cm}$. The MES_48 reactors contained WW to a height of $50 \mathrm{~cm}$, i.e. with $2 \mathrm{~cm}$ of solution above the electrode. The small reduction of the diameter and the significant increase in the height compared to the MES_26 were intended to increase the length of the upper cathode part, without disturbing the lower part, following the results obtained with the MES_26 (as explained at the beginning of part 3.2).

Each MES reactor was included in a closed hydraulic loop including a peristaltic pump (Masterflex ${ }^{\circledR}$, Cole-Parmer, USA) and a $2 \mathrm{~L}$ storage tank. The recirculation was set up at $1.5 \mathrm{~mL} \cdot \mathrm{min}^{-1}$. Forced aeration was achieved with air pumps, which bubbled air vigorously into the solution.

The titanium rod in the centre of the electrode was used to connect the MES to the electrical circuit. The potential of each MES was monitored vs. a saturated calomel reference electrode (SCE, Sentek, Australia, $0.24 \mathrm{~V} / \mathrm{SHE}$ ) using a multi-channel potentiostat (MPG, EClab software, Bio-Logic SA). All potentials were expressed vs. SCE.

\subsection{Biofilm formation and operation}

Preliminary oxygen concentration measurements were carried out in batch in an MES_26 reactor filled with WW, without the MES electrode inside. Forced aeration was set up on the top of the reactor, $2 \mathrm{~cm}$ from the free surface, for 3 hours. 
The first experimental run implemented four MES_26 in parallel, with air bubbling set on the top in two of them (as in the preliminary experiment), and at the bottom in the others. After a stabilization period of 0.7 day without aeration, forced aeration sequencing was applied manually. After 1.6 day, automatic sequential aeration was set up: 2 hours with aeration and 4 hours without. The loop initially contained $2 \mathrm{~L}$ of WW inoculated with $5 \%(\mathrm{v} / \mathrm{v})$ AS. The storage tanks were first changed after 4 days and then replaced every 3 to 4 days with tanks containing $2 \mathrm{~L}$ of only WW without AS.

The second experimental run implemented four MES_48 in parallel, two with an MES electrode and two controls with a plastic grid to replace the electrode. The control reactors were similar to the MES reactors and were equipped with the same cross structure with the same dimensions as the MES electrodes. Each of the two parts of the cross was composed of three plastic grids superimposed, so as to have a structure with the same thickness as the MES electrodes. For all 4 reactors, the aeration was set up in the upper quarter of the reactor, $12.5 \mathrm{~cm}$ from the free surface. At the beginning of the experiment, the aeration sequence was 2 hours with aeration and 4 hours without. At day 6 , it was changed to 30 minutes with aeration and 5.5 hours without. The loop initially contained 2 L of WW inoculated with $5 \%(v / v)$ AS. The storage tanks were changed on days 9 and 16 and replaced with tanks containing 2 L of WW only.

Three batch sessions were used to evaluate the removal of organic matter. For each batch, at the end of the 30 minute aeration period, the hydraulic recirculation pumps were stopped, the reactors were emptied and then refilled with around $300 \mathrm{~mL}$ of hydrolysed WW. The emptying and refilling operations were performed under a constant flux of nitrogen in order to avoid parasitic aerobic consumption of the COD. The organic matter removal was then monitored by taking successive samples from the middle of the MES reactor. COD removal rates $(\triangle \mathrm{COD})$ were calculated as:

$\triangle \operatorname{COD}(\%)=\frac{C O D_{0}-C O D_{t}}{C O D_{0}} 100$

where $C O D_{t}$ is the $C O D$ value at time $t$ and $C O D_{0}$ the initial value of the first sampling just after medium change.

\subsection{Analytical procedures}

The concentration of dissolved oxygen was measured using selfadhesive oxygen-sensitive spots (SP-PSt3-SA23-D5-YOP-US, PreSens, Germany), which were glued on the glass reactor wall at eights of $5,10,15,20$ and $25 \mathrm{~cm}$. The reading was taken through a polymer optical fibre (POF-L2.5-2SMA, PreSens, Germany).

The soluble COD was measured after filtering the samples with a syringe filter $(0.22 \mu \mathrm{m})$ using the Hach Lange LCK 314 system for concentrations ranging from 15 to $150 \mathrm{mg} \mathrm{O} \cdot \mathrm{L}^{-1}$ and LCK 514 microkits for concentrations ranging from 100 to $2,000 \mathrm{mg} \mathrm{O} \cdot \mathrm{L}^{-1}$.

\section{Results and discussion}

MESs can consist of two different electrodes connected by an electric wire [4]. This configuration allows a clear distinction to be made between anode and cathode, so the effect of the MES on COD removal can be accurately evaluated by comparing the two connected electrodes with the two unconnected electrodes, which then serve as the control.

MESs can also consist of a single piece of conductive material, such as a monolithic electrode or a bed of conductive granules [4]. In this case, it is difficult to distinguish the anode and cathode zones. These zones can vary depending on oxygen transport in the solution. Moreover, it is difficult to define a relevant control setup because it is necessary to use a different material that is not

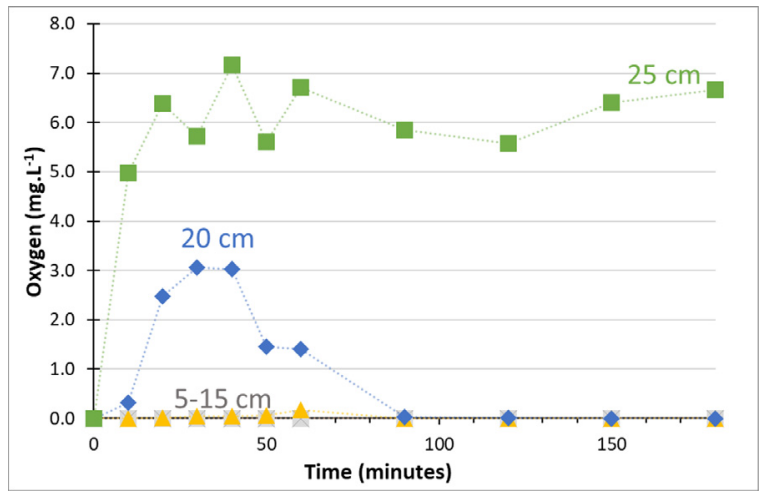

Fig. 2. Concentration of dissolved oxygen as a function of time at different heights (from the bottom) of an MES_26. Batch mode, aeration $2 \mathrm{~cm}$ below the free surface.

conductive. For example, MESs in the form of fixed beds of carbon granules have been compared to gravel beds [9] or sand filters [17], which are then used as the control.

Nevertheless, the single piece configuration was implemented here because it is closer to the configuration that could be developed at large size in treatment plants. Here, the control MESs were designed to be as close as possible to the MES conductive set-up by using plastic grids of dimensions identical to those of the carbon electrodes.

\subsection{Oxic/anoxic profile (Strategy 1) vs. bidirectional electrode (Strategy 2)}

Preliminary measurements of the dissolved oxygen concentration profile were carried out in an MES_26 reactor, filled with 27 $\mathrm{cm}$ of WW without the electrode inside. Measurements were performed in batch with continuous aeration on the top of the reactor, $2 \mathrm{~cm}$ from the free surface. Oxygen concentration reached $6.4 \mathrm{mg} . \mathrm{L}^{-1}$ in 20 minutes at the top of the reactor (height $25 \mathrm{~cm}$ ). Then the value remained fairly stable at the top with $6.2 \pm 0.6$ mg. $\mathrm{L}^{-1}$ for more than 2 hours (Fig. 2). At $20 \mathrm{~cm}$ height, the oxygen concentration rose to a maximum of $3.1 \mathrm{mg} . \mathrm{L}^{-1}$ at 30 minutes but then dropped again to 0 until the end. All the other measurements at 15,10 and $5 \mathrm{~cm}$ height showed a nil concentration during the 3 hours.

The aeration system used here made it possible to create a stable profile of dissolved oxygen with an upper oxic zone and a lower anoxic part in the MES_26 reactor. It was consequently decided to run two MES_26 with this aeration system, in order to assess Strategy 1 (see Introduction), and two other MES_26 with aeration at the bottom of the reactor to compare with Strategy 2. In both cases, the objective was to optimize the sequence of aeration.

After 0.7 day under constant hydraulic recirculation and without any aeration, the potentials of the four MES_26, which were run in parallel, were stable at $-0.42 \pm 0.01 \mathrm{~V} / \mathrm{SCE}$ (Fig. 3A). The oxygen concentration was monitored in one reactor that was aerated at the bottom. After 0.7 day, the concentration of dissolved oxygen was nil. As the measurement was made at the top of the reactor (25 cm high), $2 \mathrm{~cm}$ under the free surface of the solution, this implies that the oxygen concentration was nil in the whole reactor. When the aeration was started at 0.7 day, the potential increased rapidly, reaching $-0.13 \pm 0.01 \mathrm{~V} / \mathrm{SCE}$ within 10 minutes, and then stayed stable at $-0.05 \pm 0.07 \mathrm{~V} / \mathrm{SCE}$ during the aeration period (Fig. 3B). The oxygen concentration rose from 0 to $5.8 \mathrm{mg} . \mathrm{L}^{-1}$ within 10 minutes and then stabilized at $7.31 \pm 0.1$ mg.L $\mathrm{L}^{-1}$ during the aeration period. Aeration was then stopped and the oxygen 


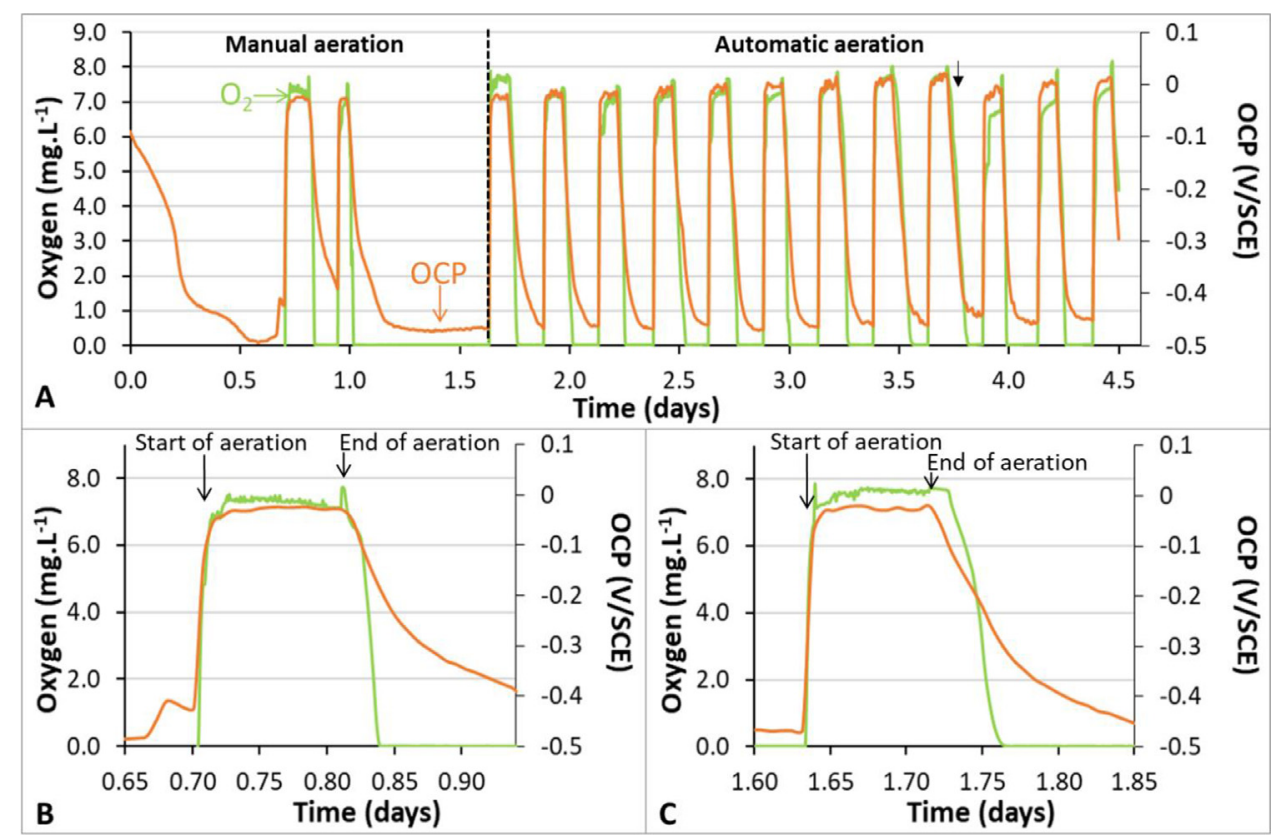

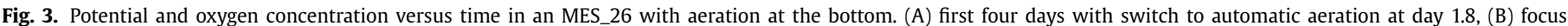

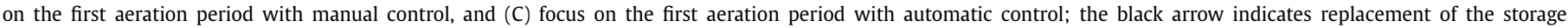
tanks.

concentration dropped to 0 within 20 minutes. It took more time, around 2.5 hours, for the potential to drop to $-0.41 \pm 0.01 \mathrm{~V} / \mathrm{SCE}$.

As explained elsewhere [4], the potential of an MES is a mixed potential, which results from the large potential gradient along the electrode, from the anode part at the bottom to the cathode part at the top. Here, the variation from the minimal value below -0.4 $\mathrm{V} / \mathrm{SCE}$ in anoxic conditions, to the maximal value close to $0.0 \mathrm{~V} / \mathrm{SCE}$ during the forced aeration period, means that the MES was driven by its anode or cathode function, respectively.

Studies on bidirectional microbial electrodes have observed similar potential variations according to aeration conditions with a high potential in the aerated cathodic phase and a low potential in the anoxic anodic phase. A similar amplitude, with a potential ranging from $-405 \mathrm{mV} / \mathrm{SCE}$ during the anodic phase to $195 \mathrm{mV} / \mathrm{SCE}$ during the cathodic phase, has been observed in a solar energy powered MFC [18]. Greater amplitude, ranging from -450 to 300 $\mathrm{mV} / \mathrm{SCE}$, has been reported for dye treatment with an MFC [19]. Larger amplitudes of potential can be measured in MFCs because the anode and the cathode are separated, so the potential is measured on an electrode that functions strictly as an anode or strictly as a cathode. In contrast, the potential of an MES is most often a mixed potential.

The objective for WW treatment is that the MES should operate at high potential in order to promote the oxidation of organic matter. The aeration periods must drive the potential to high values. Then the non-aerated periods must not leave the potential at low values for too long because, at low potential values, the MES is no longer active for the oxidation of organic matter.

With this rule in mind, the first two aeration periods, which were managed manually, showed that an aeration period of 2 hours, coupled with a period of 4 hours without aeration seemed to be a suitable sequence. Accordingly, the automatic aeration was started after 39 hours (1.6 days) with this sequence and maintained until the end of the experiment. The maximal and minimal values of potential and dissolved oxygen concentration showed fair stability during the 14 cycles (Fig. 3A). The MES worked in an appropriate way, reaching high values of potential during forced aeration and not staying at minimal potential values for too long.
As described for the first aeration period (Fig. 3B), the potential response was always delayed with respect to oxygen concentration when the aeration stopped. For instance, during the third aeration period (Fig. $3 \mathrm{C}$ ) the oxygen concentration dropped to 0 within 1 hour, while the potential dropped from $-0.01 \pm 0.01 \mathrm{~V} / \mathrm{SCE}$ to -0.43 $\pm 0.03 \mathrm{~V} / \mathrm{SCE}$ within 2.5 hours. The potential of the MES continued to decrease, when there was no longer any oxygen in solution. This showed that the MES remained able to accept electrons from organic matter even when there was no longer oxygen in solution to release them. This capacity of the MES is important because it makes it possible to lengthen the period without aeration, and thus to minimize the aeration cost. Increasing the capacitance of the MES should be a key objective for future research in order to decrease the frequency of the forced aeration phases.

The potential of the MESs monitored for 15 days showed some changes of the value of the maximal potential just after the storage tank replacement (Fig. 4). For the MESs with aeration at the top, after the tank change, the maximal potential dropped by 0.10 $\pm 0.03 \mathrm{~V} / \mathrm{SCE}$ compared to the values before the change. For the MESs with aeration at the bottom, it only dropped by $0.04 \pm 0.02$ $\mathrm{V} / \mathrm{SCE}$ (Table 1).

After each tank change, the MESs with aeration at the top had more and more difficulty in recovering high maximal values. For instance, after the second tank replacement, about 6 aeration cycles were necessary to recover a maximal potential around 0.0 $\mathrm{V} / \mathrm{SCE}$, whereas 9 were necessary after the third tank replacement (Fig. 4). This means that the cathode had more and more difficulty in raising the potential to high values when the MES was supplied with organic matter. This was due to the progressive improvement of the anode part, which became increasingly efficient and pulled the potential down when the MES was provided with organic matter. Such evolution was not observed with the MESs aerated at the bottom, probably because the oxic conditions throughout the reactor hindered the formation of an efficient microbial anode.

It should be noted that the literature reports several bidirectional microbial electrodes [15] that have shown efficient anode properties and accepted full exposure to aerated conditions. However, all these bidirectional microbial electrodes were formed with 


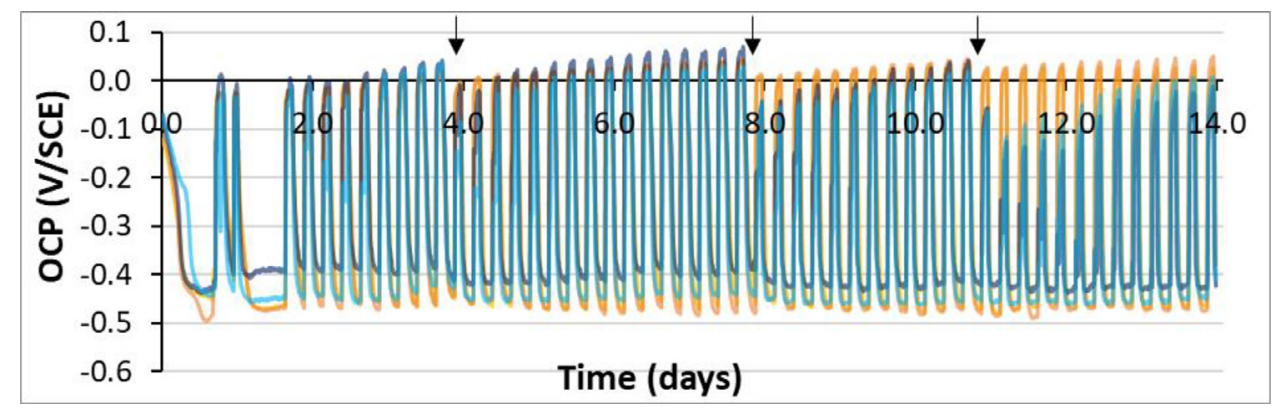

Fig. 4. Potential of the four MES_26 versus time. Two MES_26 had aeration at the top (blue) and two at the bottom (orange); black arrows indicate the tank changes

Table 1

Maximal potential before and after tank changes

\begin{tabular}{lllll}
\hline Moment & Measurement & Tank change & Aeration at top & Aeration at the bottom \\
\hline Max. & Before & 1 & $0.02 \pm 0.01$ & $0.04 \pm 0.01$ \\
Po- & tank & 2 & $0.04 \pm 0.03$ & $0.04 \pm 0.01$ \\
ten- & change & 3 & $0.03 \pm 0.02$ & $0.04 \pm 0.01$ \\
tial & After & 1 & $-0.12 \pm 0.04$ & $-0.02 \pm 0.01$ \\
(V/SCE) & tank & 2 & $-0.04 \pm 0.01$ & $0.01 \pm 0.01$ \\
& change & 3 & $-0.06 \pm 0.01$ & $0.02 \pm 0.01$ \\
\hline
\end{tabular}

an initial anode phase of several days, sometimes several weeks, performed under anaerobic conditions. Here, in the MESs aerated at the bottom, the phases of full aeration started from the beginning of the experiment. Such early aeration phases were certainly not appropriate to develop efficient microbial anodes.

Aeration from the bottom could remain a possible alternative after a first phase of microbial anode formation, which should be performed with aeration at the top. Nevertheless, this would make the set-up and protocol much more complex, particularly if the development of full sized MESs in WW treatment bioreactors is envisioned. This led us to abandon Strategy 2 based on full aeration of the MES.

\subsection{Domestic wastewater treatment}

Strategy 1 was pursued with longer MESs (MES_48). The aeration zone was enlarged in order to obtain stronger cathodes, able to balance even fully developed anode parts. Actually, the results obtained with the MES_26 showed that the cathodes formed by aeration $2 \mathrm{~cm}$ below the free surface were no longer efficient enough to drive the potential to high values when the anode became more efficient. The MES_48 were consequently aerated at the upper quarter of the reactor, $12.5 \mathrm{~cm}$ from the free surface.

Until day 6, the aeration sequence included 2 hours with aeration and 4 hours without, based on the results of MES_26. After day 6 , the aeration period was decreased to 30 minutes as this was sufficient to reach the high potential. The cycles then included a period of 30 minutes with aeration and 4.5 hours without. The potential showed the same general trend as with the MES_26, with fair stability (Fig. 5). A slight drop in potential after the storage tank changes showed that the anode parts were efficient. Nevertheless, the cathode parts managed to maintain the potential above $0.0 \mathrm{~V} / \mathrm{SCE}$ almost all the time, which showed that enlarging the aeration zone had a positive effect.

At the end of the experiment, oxygen concentration was measured as a function of time at different heights of the MES. At the end of the period without aeration, the oxygen concentration was zero in the whole reactor. After 30 minutes of aeration, the concentration remained zero at the bottom of the MES, but had increased in the middle and reached $6.7 \mathrm{mg} . \mathrm{L}^{-1}$ from $25 \mathrm{~cm}$ high to the top (Fig. 6). It can be concluded that the 30 minutes of aeration managed to establish the desired profile of dissolved oxygen concentration, with an upper, fully oxic zone and a lower zone remaining anoxic.

MES_48s showed high stability during the 27 days of operation (Fig. 5). The aeration periods allowed the MESs to reach maximal potential between $0 \mathrm{~V} / \mathrm{SCE}$, immediately after the tank changes, and $+0.1 \mathrm{~V} / \mathrm{SCE}$ when the substrate was low. The minimal potential of $-0.45 \pm 0.07 \mathrm{~V} / \mathrm{SCE}$ was very stable during the anoxic phases. Even the pauses in aeration and recirculation, which were inserted to monitor the COD abatement in batch, did not cause any variation in the maximal and minimal potential values, which returned to the same values at the end of the batch phases.

Batch phases were set just after the changes of the storage tanks in order to monitor COD abatement in batch conditions. In the first batch phase, the initial COD measurement $\left(D \mathrm{CO}_{0}\right.$ in equation 1 ) was made just after the tank change ( $t=1$ hour in Fig. $7 \mathrm{~A})$ and the second 5 hours later $(t=6$ hours in Fig. $7 \mathrm{~A})$. COD removal was $2 \pm 4 \%$ in the controls equipped with plastic structures and $32 \pm 0 \%$ in the MES_48. The snorkel effect was thus obvious. Nevertheless, COD abatement did not increase afterwards. On the contrary, it tended to decrease, with a value of $25 \pm 0.3$ $\%$ in the MES_48 after 24 hours (less than $4 \pm 6 \%$ in the control reactors). This apparent decrease of COD removal may have been due to the solubilization of solid COD or release of organic matter from the biofilm. Looking at the COD abatement in parallel with the potential evolution (Fig. 7A) reveals that there was no further abatement from the time the minimal potential was reached. The second batch therefore focused on this 4 hour period of time and the third batch focused on the first hour.

Batch 2 showed that there was no longer any COD abatement 2 hours after aeration was stopped. At this time, the potential just recovered its minimal value (Fig. 7B). Batches 2 and 3 gave similar COD removal rates 1 hour after the aeration was stopped $(2 \pm 1 \%$ and $12 \pm 2 \%$ in the controls and the MES_48, respectively). Batch 3 showed that the period of the main COD abatement was about 30 minutes after the aeration was stopped. During these 30 minutes, the potential had completed about $90 \%$ of its drop from its maximal to its minimal value (Fig. $7 \mathrm{C}$ ). The potential drop was directly correlated to the MES activity.

Physically, the electrode is emptied of electrons during the aeration phase and thus reaches its maximal potential value. When the aeration phase is stopped, the electrode collects electrons by oxidizing organic matter. The MES is thus active and abates the 


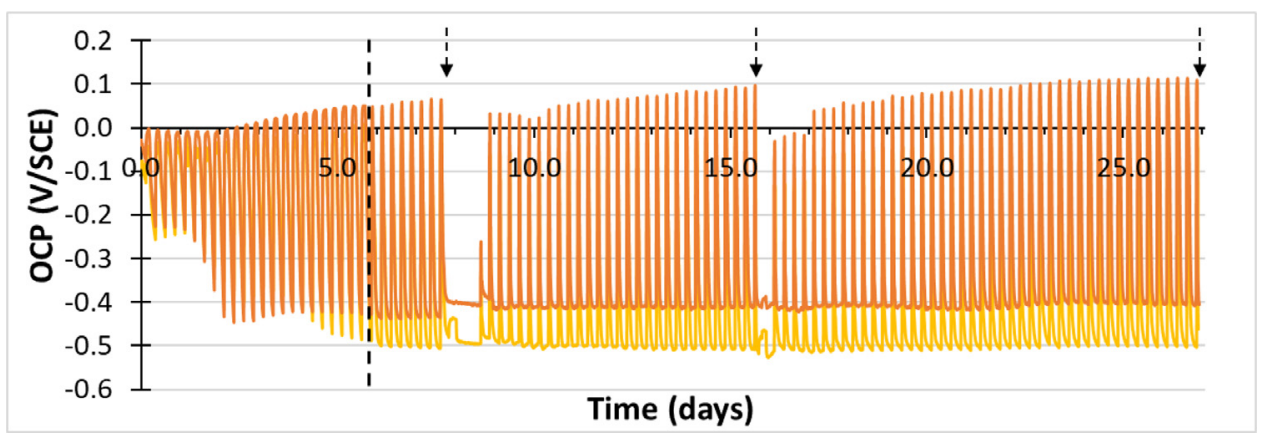

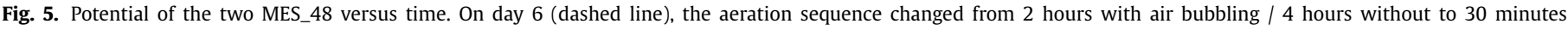
with / 5.5 hours without. COD monitoring in batch took place at days 7, 15 and 27 (dashed arrows).

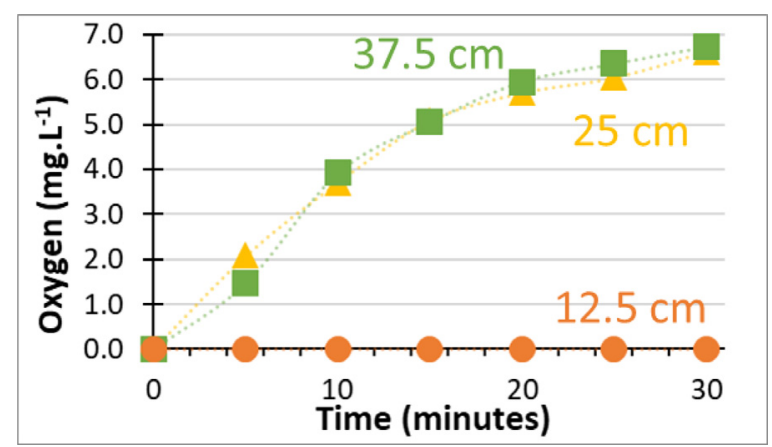

Fig. 6. Oxygen concentration versus time at different heights (from the bottom) of an MES_48 during the aeration period

organic matter. Once the electrode recovers the highest amount of electrons it can contain, the minimal value of the potential is reached and the oxidation can no longer continue.

The three batches showed the efficiency of the MES_48. COD removal rates were always significantly higher than in the control reactors equipped with a plastic structure. For Batch 1, the MESs removed 6.3 times more COD than the controls did $(25 \pm 0.3 \%$ vs $4 \pm 6 \%$ ). The result was slightly lower for Batch 2, with 5.7 times greater removal rates ( $17 \pm 2 \%$ vs $3 \pm 2 \% 4$ hours after aeration was stopped). Batch 3 led to 3 times greater removal rates with the MES ( $12 \pm 1 \%$ vs $3 \pm 0.1 \%$ ) 1 hour after aeration was stopped.

These COD abatement rates seem modest compared to some high values reported in the literature, for instance, the $60-75 \%$ obtained with an MES for wastewater treatment [3]. However, the data presented here are very encouraging considering that the MES_48 worked for only around 2 hours after the cessation of aeration and achieved the majority of the COD abatement in only 30 minutes. Here, the objective was to advance in deciphering the MES behaviour. For this reason, the COD abatement was monitored in batch, during the period of non-aeration, in order to really identify the MES effect and to distinguish it from the aeration effect. To be fair, the comparison had to be made between the same reactors, operated in the same way and equipped or not with an MES. This comparison showed that the MES multiplied the removal rates by a factor of 3 to 6.3 depending on the batch and the time it lasted.

The approach taken here affords useful information for progress to be made in optimizing the operating conditions of MESs. First of all, it should be emphasized that measuring the MES potential
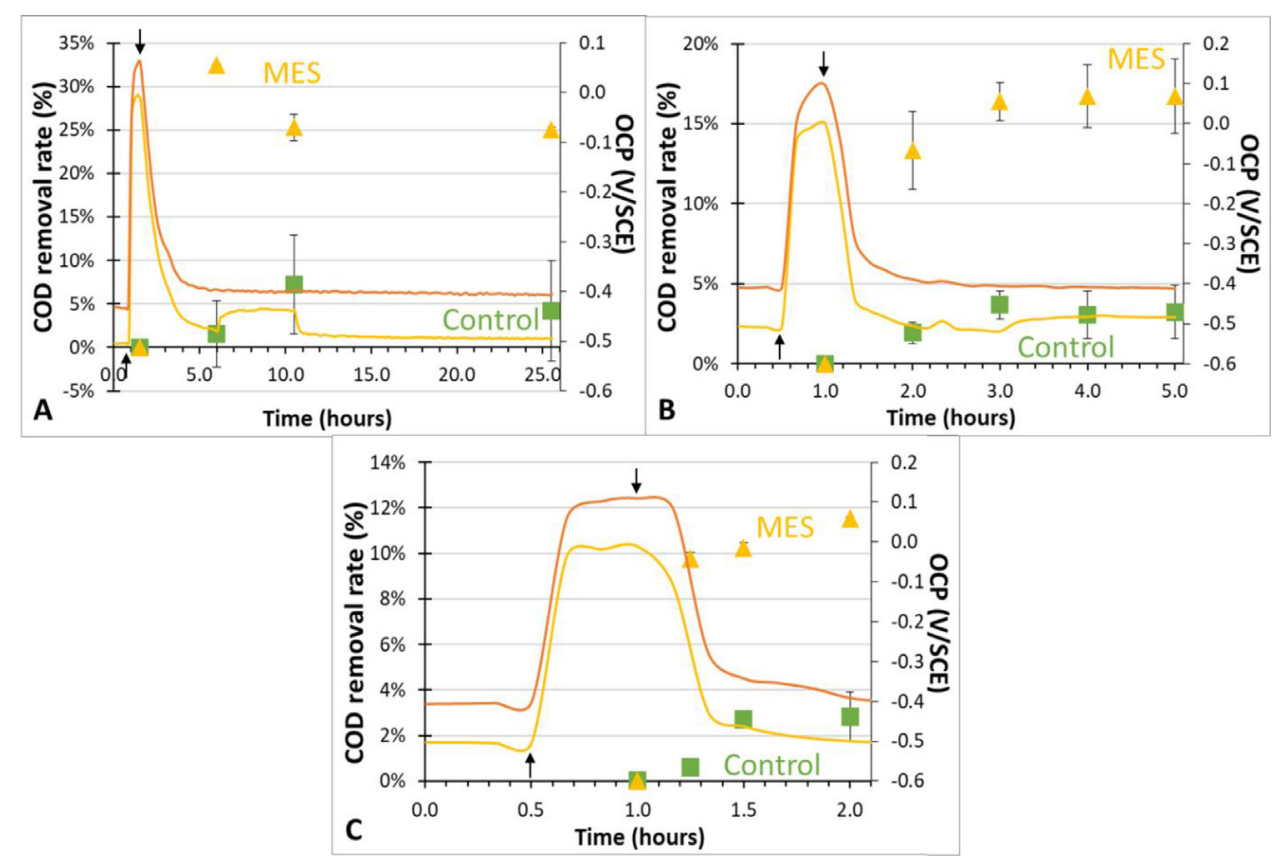

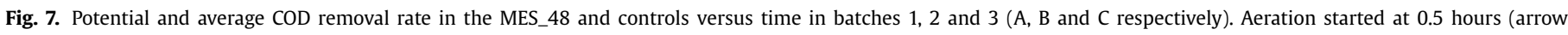
up) and stopped 30 minutes later (arrow down). The medium was then changed, recirculation was stopped and COD measurements began. 
must now be considered as the essential parameter to control the MES operation. A clear correlation was pointed out here between the MES potential, oxygen concentration and MES activity. This correlation now gives clear practical rules for running MES reactors in conditions that are as close as possible to optimal, including optimization of the aeration frequency and of the aeration location. These practical rules can be summarized as follows:

- Aeration must pull the MES potential to its maximal value of about $0.1 \mathrm{~V} / \mathrm{SCE}$ and it can be stopped when this potential is reached.

- During the non-aeration periods, the MES is active for organic matter oxidation as long as the minimal value of the potential is not reached. When the minimal value is reached $(-0.4$ to -0.5 $\mathrm{V} / \mathrm{SCE}$ ), aeration must be restarted.

- Aeration must be performed in the upper zone of the MES and keep an anoxic zone at the bottom (Strategy 1). Actually, aeration of the whole MES length (Strategy 2) is detrimental to the initial formation of the microbial anode.

- A significant decrease of the value of maximal potential when organic matter is supplied to the MES indicates that the cathode is not strong enough to drive the potential towards high values and that the upper aeration zone must be enlarged.

In addition, it was pointed out that the activity of the MES for organic matter oxidation during the non-aerated periods depends on its capacity to accumulate electrons. Consequently, the more capacitive the electrode is, the more capable it will be of storing electrons, enabling longer non-aerated periods. Increasing the capacitance of the MES material should consequently be a way to space out the aeration periods, and thus to decrease the aeration cost. The interest of capacitive materials has been widely investigated in the domain of microbial fuel cells [20-24]. The considerable experience gained in this context should be very useful in improving MESs by reducing the frequency of aeration.

\section{Conclusion}

Potential has been demonstrated to be the key parameter that should be monitored to manage an MES here, particularly when setting the aeration zone and controlling the aeration frequency. To the best of our knowledge, this is the first time that a correlation has been shown between the MES potential and the dissolved oxygen concentration. Practical rules have thus been stated for using the potential measurement to control the aeration frequency and set the aeration location in the MES reactors. The period of activity of the MES after the end of the aeration was about 30 minutes here. During these 30 minutes, the MESs abated 3 to 6.3 times more COD than the controls. This active period without aeration corresponds to the time required for the electrode to reach its maximal level of accumulation of the electrons coming from the oxidation of organic matter. Increasing the capacitance of the MES material should therefore be a research priority to improve the system further by decreasing the aeration frequency.

\section{Author's role}

Morgane HOAREAU: Conceptualization, Methodology, Investigation, Writing - Original Draft.

Luc ETCHEVERRY: Conceptualization, Methodology.

Benjamin ERABLE: Conceptualization, Methodology, Validation, Supervision.

Alain BERGEL: Conceptualization, Validation, Writing - Original Draft, Writing - Review \& Editing, Supervision, Project.

\section{Declaration of competing interest}

The authors declare that they have no known competing financial interests or personal relationships that could have appeared to influence the work reported in this paper.

\section{Acknowledgements}

This work was supported by the French Agence Nationale de la Recherche (ANR), within the framework of the Biotuba project (ANR-17-CE06-0015).

\section{References}

[1] D. Fang, B. Chen, Linkage analysis for the water-energy nexus of city, Appl. Energy 189 (2017) 770-779, doi:10.1016/j.apenergy.2016.04.020.

[2] M. Molinos-Senante, R. Sala-Garrido, A. Iftimi, Energy intensity modeling for wastewater treatment technologies, Sci. Total Environ. 630 (2018) 1565-1572, doi:10.1016/j.scitotenv.2018.02.327.

[3] B. Erable, L. Etcheverry, A. Bergel, From microbial fuel cell (MFC) to microbial electrochemical snorkel (MES): maximizing chemical oxygen demand (COD) removal from wastewater, Biofouling 27 (2011) 319-326, doi:10.1080/ 08927014.2011.564615

[4] M. Hoareau, B. Erable, A. Bergel, Microbial electrochemical snorkels (MESs): A budding technology for multiple applications. A mini review, Electrochem. Commun. 104 (2019) 106473, doi:10.1016/j.elecom.2019.05.022.

[5] C. Cruz Viggi, E. Presta, M. Bellagamba, S. Kaciulis, S.K. Balijepalli, G. Zanaroli, M. Petrangeli Papini, S. Rossetti, F. Aulenta, The "Oil-Spill Snorkel": an innovative bioelectrochemical approach to accelerate hydrocarbons biodegradation in marine sediments, Front. Microbiol. 6 (2015), doi:10.3389/fmicb.2015.00881.

[6] U. Marzocchi, E. Palma, S. Rossetti, F. Aulenta, A. Scoma, Parallel artificial and biological electric circuits power petroleum decontamination: the case of snorkel and cable bacteria, Water Res. 173 (2020) 115520, doi:10.1016/j.watres. 2020.115520.

[7] Q. Yang, H. Zhao, H. Liang, Denitrification of overlying water by microbial electrochemical snorkel, Bioresour. Technol. 197 (2015) 512-514, doi:10.1016/ j.biortech.2015.08.127.

[8] A. Aguirre-Sierra, T. Bacchetti-De Gregoris, J.J. Salas, A. de Deus, A. EsteveNúñez, A new concept in constructed wetlands: assessment of aerobic electroconductive biofilters, Environ. Sci.: Water Res. Technol. 6 (2020) 1312-1323, doi:10.1039/C9EW00696F.

[9] A. Aguirre-Sierra, T. Bacchetti-De Gregoris, A. Berná, J.J. Salas, C. Aragón, A. Esteve-Núñez, Microbial electrochemical systems outperform fixed-bed biofilters in cleaning up urban wastewater, Environ. Sci.: Water Res. Technol. 2 (2016) 984-993, doi:10.1039/C6EW00172F.

[10] C.A.Arias Ramírez-Vargas, L. Zhang, H. Brix, Microbial community function in electroactive biofilm-based constructed wetlands, Biogeosci. Discuss. (2018) 128, doi:10.5194/bg-2018-428.

[11] C.A. Ramírez-Vargas, C.A. Arias, P. Carvalho, L. Zhang, A. Esteve-Núñez, H. Brix, Electroactive biofilm-based constructed wetland (EABB-CW): A mesocosmscale test of an innovative setup for wastewater treatment, Sci. Total Environ. 659 (2019) 796-806, doi:10.1016/j.scitotenv.2018.12.432.

[12] M. Rimboud, M. Barakat, A. Bergel, B. Erable, Different methods used to form oxygen reducing biocathodes lead to different biomass quantities, bacterial communities, and electrochemical kinetics, Bioelectrochemistry 116 (2017) 2432, doi:10.1016/j.bioelechem.2017.03.001.

[13] B. Erable, D. Féron, A. Bergel, Microbial Catalysis of the Oxygen Reduction Reaction for Microbial Fuel Cells: A Review, ChemSusChem 5 (2012) 975-987, doi:10.1002/cssc.201100836.

[14] M. Rimboud, A. Bergel, B. Erable, Multiple electron transfer systems in oxygen reducing biocathodes revealed by different conditions of aeration/agitation, Bioelectrochemistry 110 (2016) 46-51, doi:10.1016/j.bioelechem.2016.03.002.

[15] M. Hoareau, B. Erable, A. Bergel, Oxygen-reducing bidirectional microbial electrodes: A mini-review, Electrochem. Commun. (2021) 106930, doi:10.1016/j. elecom.2021.106930

[16] M. Hoareau, B. Erable, O. Chapleur, C. Midoux, C. Bureau, A. Goubet, A. Bergel, Oxygen-reducing bidirectional microbial electrodes designed in real domestic wastewater, Bioresour. Technol. (2021).

[17] C.A. Ramírez-Vargas, C.A. Arias, P. Carvalho, L. Zhang, A. Esteve-Núñez, H. Brix, Electroactive biofilm-based constructed wetland (EABB-CW): a mesocosmscale test of an innovative setup for wastewater treatment, Sci.Total Environ 659 (2019) 796-806, doi:10.1016/j.scitotenv.2018.12.432.

[18] D.P.B.T.B. Strik, H.V.M. Hamelers, C.J.N. Buisman, Solar Energy Powered Microbial Fuel Cell with a Reversible Bioelectrode, Environ. Sci. Technol. 44 (2010) 532-537, doi:10.1021/es902435v.

[19] J. Sun, Y. Hu, W. Li, Y. Zhang, J. Chen, F. Deng, Sequential decolorization of azo dye and mineralization of decolorization liquid coupled with bioelectricity generation using a $\mathrm{pH}$ self-neutralized photobioelectrochemical system operated with polarity reversion, J. Hazard. Mater. 289 (2015) 108-117, doi:10.1016/j.jhazmat.2015.02.010.

[20] A. Deeke, T.H.J.A. Sleutels, A.T. Heijne, H.V.M. Hamelers, C.J.N. Buisman, Influence of the thickness of the capacitive layer on the performance of bioan- 
odes in Microbial Fuel Cells, J. Power Sources 243 (2013) 611-616, doi:10.1016/ j.jpowsour.2013.05.195.

[21] C. Borsje, D. Liu, T.H.J.A. Sleutels, C.J.N. Buisman, A. ter Heijne, Performance of single carbon granules as perspective for larger scale capacitive bioanodes, J. Power Sources 325 (2016) 690-696, doi:10.1016/j.jpowsour.2016.06.092.

[22] B. Li, J. Zhou, X. Zhou, X. Wang, B. Li, C. Santoro, M. Grattieri, S. Babanova, K. Artyushkova, P. Atanassov, A.J. Schuler, Surface modification of microbial fuel cells anodes: approaches to practical design, Electrochim. Acta 134 (2014) 116-126, doi:10.1016/j.electacta.2014.04.136.
[23] C. Santoro, M. Kodali, S. Kabir, F. Soavi, A. Serov, P. Atanassov, Threedimensional graphene nanosheets as cathode catalysts in standard and supercapacitive microbial fuel cell, J. Power Sources 356 (2017) 371-380, doi:10. 1016/j.jpowsour.2017.03.135.

[24] L. Caizán-Juanarena, C. Borsje, T. Sleutels, D. Yntema, C. Santoro, I. Ieropoulos, F. Soavi, A. ter Heijne, Combination of bioelectrochemical systems and electrochemical capacitors: Principles, analysis and opportunities, Biotechnol. Adv. 39 (2020) 107456, doi:10.1016/j.biotechadv.2019.107456. 